\title{
EPOXY POLYMERS REINFORCED WITH CARBON MICROFIBRE WASTES
}

\section{Thaís da Costa Dias ${ }^{1}$, Túlio Hallak Panzera ${ }^{1 *}$, Rodrigo Teixeira Santos Freire ${ }^{1,2}$, Carlos Thomas $^{3}$, Júlio César dos Santos ${ }^{2}$ and Fabrizio Scarpa ${ }^{4}$}

(1) Centre for Innovation and Technology in Composite Materials, Department of Mechanical Engineering, Federal University of São João del Rei, Brazil. *panzera@ufsj.edu.br

(2) Centre for Innovation and Technology in Composite Materials, Department of Natural Sciences, Federal University of São João del Rei, Brazil.

(3) Laboratory of Materials Science and Engineering - LADICIM, University of Cantabria. E.T.S. de Ingenieros de Caminos, Canales y Puertos, Av/Los Castros 44, 39005 Santander, Spain.

(4) Bristol Composites Institute (ACCIS), University of Bristol, BS8 1TR Bristol, UK.

\begin{abstract}
This work investigates the incorporation of disposed carbon microfibres (CMF) obtained from the cutting process of laminate composites into epoxy polymers at different mass fractions $(0$, $2.5,5,7.5$ and $10 \mathrm{wt} \%$ ). The elastic modulus and strength under tensile, compressive, flexural loads and impact resistance are investigated via Analysis of Variance (ANOVA). The tensile (compressive) modulus progressively increases up to $36.6 \%(28.6 \%)$ with the inclusion of CMF. The inclusion of $5 \mathrm{wt} \% \mathrm{CMF}$ results in an increase of $27 \%(19 \%)$ in tensile (compressive) strength. The flexural strength also increases $28.6 \%$ when $10 \mathrm{wt} \% \mathrm{CMF}$ is added. CMF waste leads, however, to a dramatic decrease (approx. 50\%) in impact resistance attributed to the increase in stiffness.
\end{abstract}

Keywords: recycling, epoxy polymers, carbon microfibre, mechanical properties, analysis of variance. 


\section{INTRODUCTION}

The demand for composite materials has progressively increased in various technological applications due to their low density and improved mechanical performance compared to conventional materials. However, the fabrication of such materials generates waste that may lead to environmental damage if improperly disposed of. Landfills are the most common strategy, but several countries have already limited or banned the disposal of composites in landfills due to environmental issues [1-3]. Polymer composites, especially thermosets, dominate the global market and, owing to their long-life cycle, alternatives to landfills need to be sought and boosted. Mechanical, thermal and chemical recycling have been developed in order to address this problem.

Mechanical recycling involves shredding and grinding and the subsequent separation of the fibre-rich fractions for reuse [4]. Mechanically recycled composites are usually reincorporated into new composites as fillers or reinforcement [1]. Thermal processes have also been developed for energy recovery (combustion of the composite waste) or selective material recovery for reuse (fluidized beds and pyrolysis). In pyrolysis, for example, a large amount of thermal energy is required in order to remove the matrix phase. Chemical recycling involves the decomposition of the polymeric structure and the high-quality end products (monomers, hydrocarbon molecules, gases and chemical intermediates for polymerization) are reused to produce new components [5].

The literature suggests that wastes from the manufacture of composites can also be reused in recycled composites. The CarbonTek S.L. ${ }^{\circledR}$ company (Spain) has recently used powder waste resulting from the cutting process of carbon fibre-based products as polymeric matrix reinforcements for the fabrication of carbon components, as well as to reduce the volume of waste generated [6]. The residue is composed of carbon microfibres (CMF) coated with epoxy polymer, sometimes with pigment particles used to produce fins. Thomas et al. [6] evaluated the effect of CMF wastes inclusions at three different mass fractions $(0,10$ and 20 $\mathrm{wt} \%$ ) on the thermal and mechanical properties of epoxy composite materials. These authors reported an increase in compressive and flexural strength and impact resistance proportional to the mass fraction of residues. Although less significantly, hardness and erosion resistance also increased with waste inclusion. The use of waste at $10 \mathrm{wt} \%(20 \mathrm{wt} \%)$ increased the compressive strength by $6 \%(20 \%)$ relative to the pure polymer, being attributed to the additional energy expended by the cracks to overcome the micro fibres and particles. Also, the CMF is used as cement matrix reinforcement improving mechanical properties [7]. 
Compared to most recycling processes, the methodology proposed by Thomas et al. [6] is economically more feasible. Therefore, this work further investigates the effect of different mass fractions of CMF wastes on the mechanical properties of thermosetting polymers, extending the analysis to tensile modulus and strength.

\section{MATERIALS AND METHODS}

CMF, supplied by the company CarbonTek S.L. ${ }^{\circledR}$ (Spain), are obtained from the cutting process of laminate composites used in the manufacture of fins. Figure 1a shows a pair of CarbonTek carbon fins, after the cutting and assembly processes. Figure $1 \mathrm{~b}$ presents the cutting process leftovers. The fin-cutting process generates a powder that can be considered as CMF enveloped by a polymer matrix (Figure 1c).
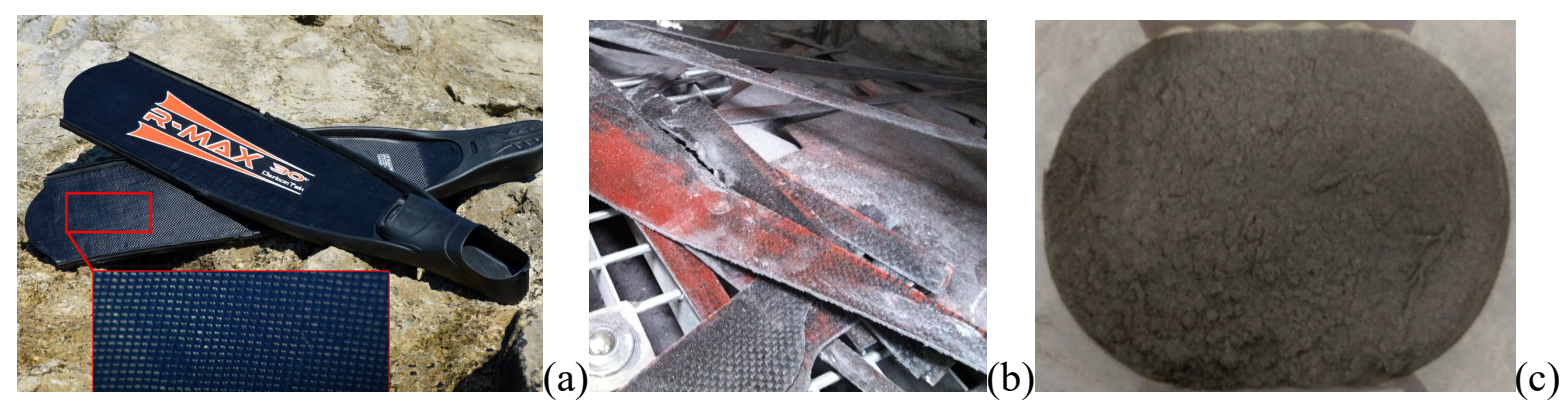

Figure 1. Fins (a), remains (b) and powder collected after the cutting process (c) [6].

The particle size distribution of the CMF is performed by sieving at the range of 100 200 US-Tyler $(0.149-0.074 \mathrm{~mm})$. These CMF are incorporated into the epoxy polymeric matrix (Resin MX-14 and hardener Aradur HY 951, resin/hardener proportion of 10:1, supplied by Huntsman). The wastes are mixed to the epoxy matrix phase in the following mass fractions: $0 ; 2.5 ; 5 ; 7.5 ; 10 \%$. For each condition 5 specimens are fabricated for each type of test (tensile, compression, flexural and impact) and later replicated. The components are hand-mixed for 5 minutes and left for a curing period of 2 weeks to finally undergo mechanical testing.

\subsection{Mechanical tests}

Tensile, compressive and flexural tests are performed in a Shimadzu AG-X Plus testing machine (Figure 3a) equipped with a $100 \mathrm{kN}$ load cell, at a crosshead speed of $2 \mathrm{~mm} / \mathrm{min}$, 
according to ASTM D638-14 [8], ASTM D695 [9], ASTM D790 [10] standards. The elongation of the specimens is measured using a digital video-extensometer. Impact tests were performed in an XJJ series impact testing machine with a $15 \mathrm{~J}$ hammer (Figure $3 \mathrm{~b}$ ) according to ASTM D6110 [11].

\subsection{Scanning Electron Microscopy}

A TM3000 Hitachi Analytical Microscope apparatus is used to investigate the morphological aspects of the CMFs as well as the surface of the fractured samples. The images are obtained in secondary electron mode at $15 \mathrm{kV}$.

\subsection{Statistical Analysis}

The experimental data are analysed via Analysis of Variance (ANOVA) and Tukey's test using Minitab Software v.17, within a 95\% confidence interval. The letters in the effect plots represent the results obtained by the Tukey comparison test; similar letters belong to the same group indicating there is no significant variation between the means.

\section{RESULTS}

Table 1 shows the ANOVA results. P-values shown in Table 1 are less than 0.05 , which reveals that the incorporation of CMFs significantly affects all response variables.

Table 1: Analysis of Variance

\begin{tabular}{ll}
\hline Mean properties & P-value \\
\hline Tensile Modulus & 0.000 \\
Tensile Strength & 0.002 \\
Compressive Modulus & 0.000 \\
Compressive Strength & 0.000 \\
Flexural Strength & 0.000 \\
Impact Resistance & 0.000 \\
\hline
\end{tabular}

The mean values of tensile modulus range from 1.42 to $1.94 \mathrm{GPa}$ (Figure 2a). Tukey's test indicates that CMF inclusions increase the stiffness at all levels. In particular, for $10 \mathrm{wt} \%$, 
the tensile modulus is $36.6 \%$ higher relative to the reference level (non-particulate samples). Tensile strength data range from 28.83 to $36.87 \mathrm{MPa}$ (Figure 2b). Based on Tukey's test, CMFs increase the tensile strength at all levels, especially at $5 \mathrm{wt} \%$ (30\% above the reference level).
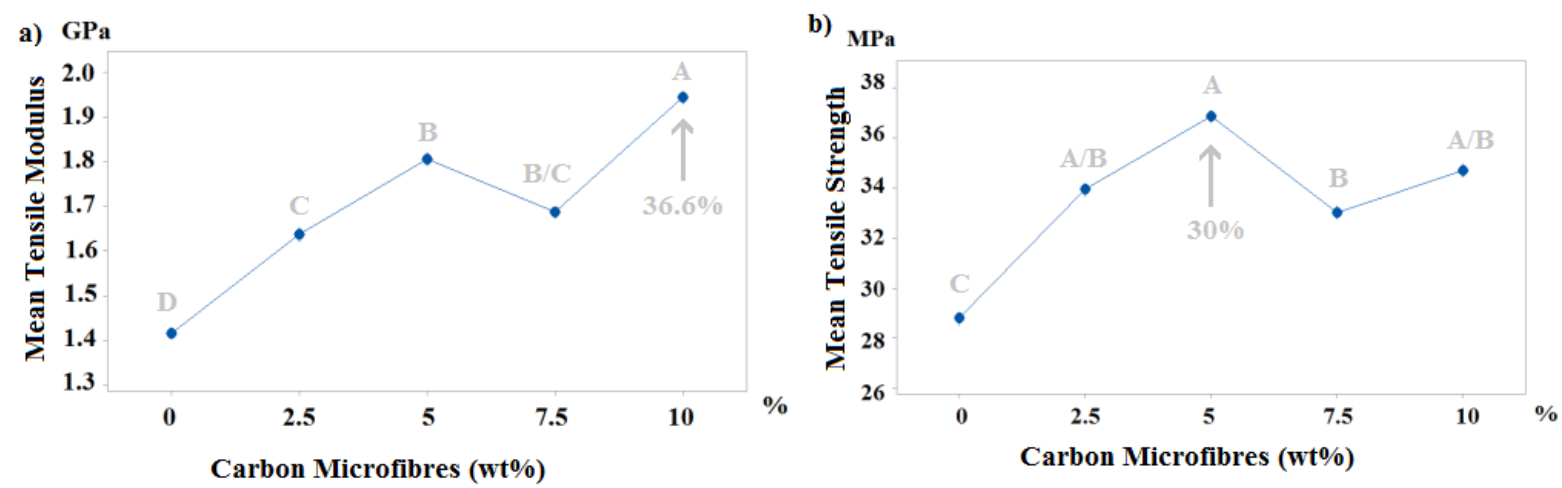

Figure 2. Main effect plot for mean tensile (a) modulus and (b) strength.

The mean compressive moduli range from 1.47 to $1.89 \mathrm{GPa}$ (Figure 3a). According to Tukey's test, the incorporation of $7.5 \mathrm{wt} \%$ and $10 \mathrm{wt} \%$ resulted similar (Group $\mathrm{A}$ and $\mathrm{AB}$ ), exhibiting a significant increase of $28.6 \%$ relative to the reference. The mean compressive strength values range from 50.06 to $59.64 \mathrm{MPa}$ (Figure 5b), with an enhancement of approximately $19 \%$ when $5 \mathrm{wt} \%$ CMFs are added. Such behaviour can be attributed to the bridging effect obtained by the presence of microfibres which delays the propagation of the cracks. Behind the crack front, bridging fibres stretch freely along the cracking faces absorbing energy, which would otherwise be available at the crack tip.
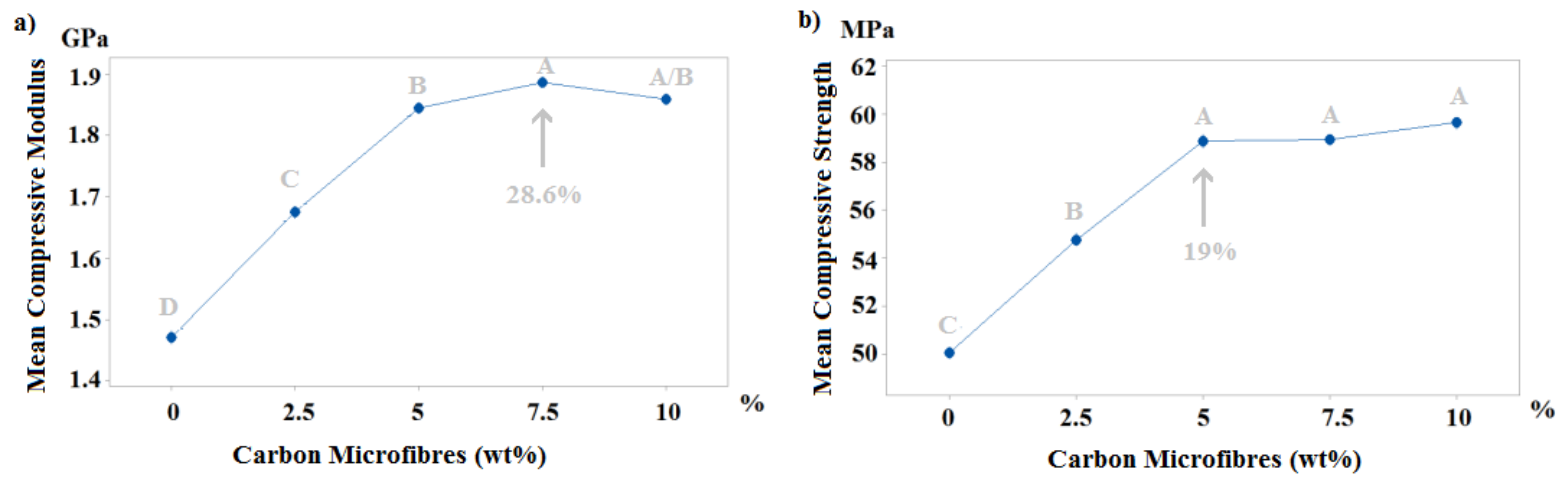

Figure 3. Main effect plot for mean compressive (a) modulus and (b) strength.

The flexural strength data range from 30.11 to $36.94 \mathrm{MPa}$ (Figure 4a). According to Tukey's test, the effect of 7.5 and $10 \mathrm{wt} \%$ CMF inclusions is similar (Group A), with an 
increase of approximately $23 \%$ relative to the reference. The impact resistance values vary from 6.53 to $15.64 \mathrm{~kJ} / \mathrm{m}^{2}$ (Figure $4 \mathrm{~b}$ ). All levels of particle inclusions lead to a dramatic reduction of the impact resistance (approx. 55\%). This behaviour may be attributed to the increased stiffness of the reinforced composites, which makes the material more brittle and consequently reduces the impact resistance.
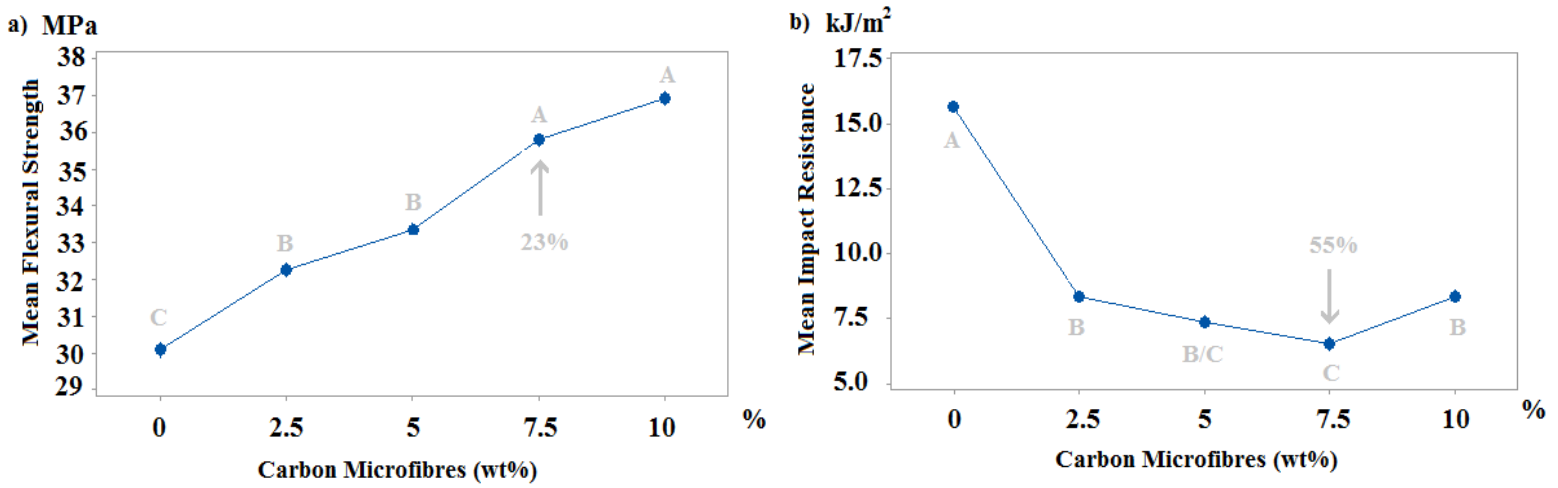

Figure 4. Main effect plot for (a) mean flexural strength and (b) impact resistance.

The microstructural analysis reveals the presence of spherical particles among carbon microfibres (Figure 5a). Such particles are metal oxides used as pigments during the fabrication of fins. Figure $5 \mathrm{~b}$ presents the fractured surface of a specimen after the tensile test with $10 \mathrm{wt} \% \mathrm{CMF}$ inclusions at $\times 100$ of magnification.

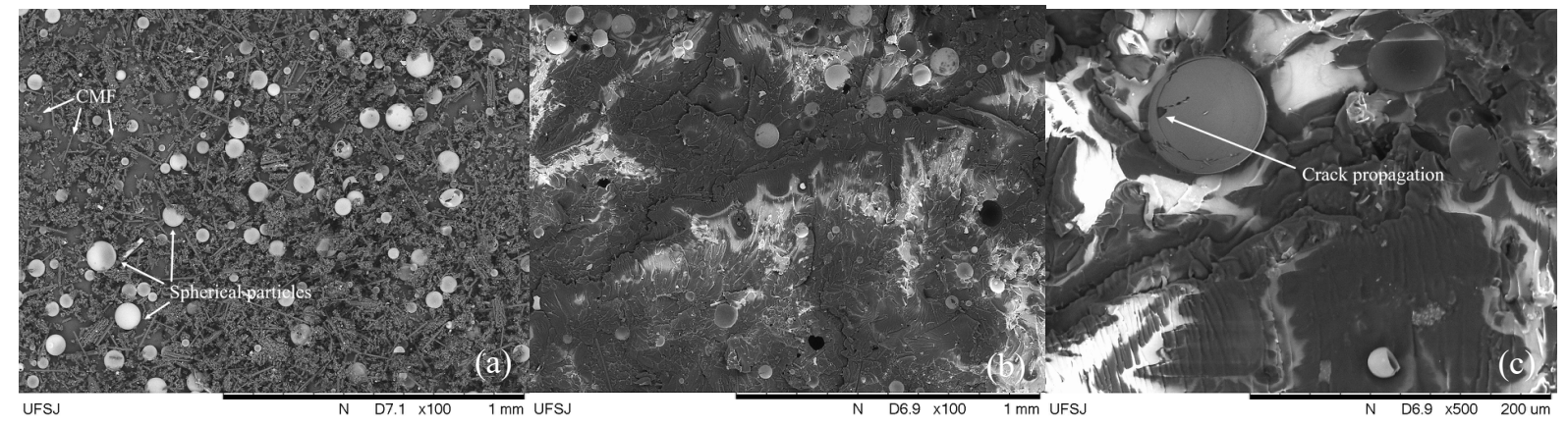

Figure 5. CMFs in pristine (a) and fractured region of the reinforced polymer $(10 \mathrm{wt} \%$ $\mathrm{CMF})$ at $\times 100(\mathrm{~b})$ and at $\times 500(\mathrm{c})$ magnification.

Figure $5 \mathrm{c}$ shows the same region with $\mathrm{x} 500$ magnification, where it is possible to observe the crack propagation along a spherical particle. During crack propagation, such rigid particles may function as barriers along the interface due to their high strength, inhibiting 
crack growth with subsequent enhancement of mechanical properties $[10,15,16]$. Thomas et $a l$. in fact reported that the inclusion of these wastes generally improved the stiffness and strength of the epoxy polymer composites, including under impact loadings [6]. In contrast, a substantial reduction in impact resistance is observed in this study, as discussed above. According to Dassios [15] fibre pull-out is the most important mechanism of impact energy dissipation in fibre-reinforced composites. It is worth noting that no evidence of fibre pull-out is observed here. However, such mechanism is shown in the fractographic analysis reported by Thomas et al. [6] and may therefore explain the increase in impact resistance.

\section{CONCLUSIONS}

The incorporation of carbon microfibres wastes into epoxy polymer promotes an increase in tensile modulus and strength. Results indicate an increase in tensile modulus (strength) up to $36.6 \%(30 \%)$ for $10 \mathrm{wt} \%(5 \mathrm{wt} \%)$ waste inclusions. Similar results are observed for compressive modulus and strength and for flexural strength. The compressive modulus (strength) increased up to $28.6 \%(19 \%)$ for $7.5 \mathrm{wt} \%$ or more $(5 \mathrm{wt} \%)$ of waste inclusions. The flexural strength increased up to $22 \%$ for $7.5 \mathrm{wt} \%$ and $10 \mathrm{wt} \%$ of CMFs. In contrast, the increased stiffness renders the material more brittle and therefore dramatically reduces the impact strength in 55\% for all waste mass fraction levels considered. Carbon fibre wastes derived from the cutting process of laminate composites can therefore be employed as epoxy polymeric matrix reinforcement so as to promote significant enhancements of stiffness and strength. In addition, this low-cost recycling process prevents improper waste disposal with environmental, economic and structural benefits.

\section{ACKNOWLEDGMENTS}

The authors would like to thank CarbonTek S.L. ${ }^{\circledR}$ for the carbon microfibre wastes used in this work and also CAPES (MSc scholarship), CNPq (PP-306767/2016-3 \& PDE205255/2017-5) and FAPEMIG (PPM-00075-17) for the financial support provided.

\section{REFERENCES}

[1] S. J. Pickering, Recycling technologies for thermoset composite materials - current status. Compos Part A: Appl Sci Manuf 2006;37(8):1206-15.

doi: 10.1016/j.compositesa.2005.05.030. 
[2] D. Khale, R. Chaudhary, Mechanism of geopolymerization and factor influencing its development: a review. J Mater Sci 2007;42:729-46.

doi: 10.1007Qs10853-006-0401-4.

[3] S. Feih, E. Boiocchi, G. Mathys, Z. Mathys, A. G. Gibson, A. P. Mouritz, Mechanical properties of thermally-treated and recycled glass fibres. Compos Part B: Eng 2011;42(3):350-8. 4. doi: 10.1016/j.compositesb.2010.12.020

[4] Y. Yang, R. Boom, B. Irion, D. van Heerden, P. Kuiper, H. de Wit. Recycling of composite materials. Chem Eng Process: Process Intensification 2012;51(0):53-68. doi: 10.1016/j.cep.2011.09.007

[5] S. Manrich, Identificação de Polímeros: Uma ferramenta para a Reciclagem. São Carlos. EDUFSCAR, 1997.

[6] C. Thomas, P. H. R. Borges, T. H. Panzera, A. Cimentada, I. Lombillo, Epoxy composites containing CFRP power wastes. Composites: Part B 59 (2014) 260- 268. doi: 10.1016/j.compositesb.2013.12.013.

[7] Norambuena-Contreras, J., Thomas, C., Borinaga-Trevi $\tilde{A} \pm 0$, R., Lombillo, I. Influence of recycled carbon powder waste addition on the physical and mechanical properties of cement pastes (2016) Materials and Structures/Materiaux et Constructions, 49 (12), pp. 5147-5159. DOI: $10.1617 / \mathrm{s} 11527-016-0850-4$

[8] ASTM Standard D638-14. 2014. "Standard Test Method for Tensile Properties of Plastics". ASTM International.

[9] ASTM Standard D695-15. 2015. "Standard Test Method for Compressive Properties of Rigid Plastics". ASTM International.

[10] ASTM Standard D790. 2015. "Standard Test Methods for Flexural Properties of Unreinforced and Reinforced Plastics and Electrical Insulation Materials1". ASTM International.

[11] ASTM Standard D6110-10. 2010. "Standard Test Method for Determing the Charpy Impact Resistance of Notched Specimens of Plastics". ASTM International.

[12] Y. Cao, J. Cameron, Impact Properties of Silica Particle Modified Glass Fiber Reinforced Epoxy Composite, J. Reinf. Plast. Compos. 25 (2006) 761-769. doi:10.1177/0731684406063536. 
[13] U. Szeluga, B. Kumanek, B. Trzebicka, Synergy in hybrid polymer/nanocarbon composites. A review, Compos. Part A Appl. Sci. Manuf. 73 (2015) 204-231. doi:10.1016/j.compositesa.2015.02.021.

[14] Y. Cao, J. Cameron, Flexural and shear properties of silica particle modified glass fiber reinforced epoxy composite, J. Reinf. Plast. Compos. 25 (2006) 347-359. doi:10.1177/0731684405056450.

[15] K.G. Dassios, A review of the pull-out mechanism in the fracture of brittle- matrix fibrereinforced composites, Adv. Compos. Lett. (2007) 17-24. 